\title{
A Compact Triple Band Metamaterial Inspired Bandpass Filter Using Inverted S-shape Resonator
}

\author{
Dilip Kumar CHOUDHARY, Raghvendra Kumar CHAUDHARY
}

Dept. of Electronics Engineering, Indian Inst. of Technology (Indian School of Mines), Dhanbad 826004, Jharkhand, India

dilip.choudhary6@gmail.com,raghvendra.chaudhary@gmail.com

Submitted September 12, 2017 / Accepted April 16, 2018

\begin{abstract}
This paper presents the compact metamaterial inspired triple-band filter using two inverted S-shape resonators and two $C$-shape stubs with via. The proposed filter is printed on FR-4 epoxy glass substrate with $1.6 \mathrm{~mm}$ thickness. The 3-dB measured fractional bandwidths are $40 \% \quad(1.6-2.4 \mathrm{GHz}), \quad 16.5 \% \quad(3.9-4.6 \mathrm{GHz})$ and $14.3 \%$ $(5.2-6.0 \mathrm{GHz})$ at center frequencies $2.0 \mathrm{GHz}, 4.25 \mathrm{GHz}$ and $5.6 \mathrm{GHz}$, respectively. This filter offers electrical circuit size of $0.22 \lambda_{g} \times 0.16 \lambda_{g}$ where given $\lambda_{g}$ is the guided wavelength at center frequency of the first passband $2.0 \mathrm{GHz}$. The performance parameter of the designed filter have been characterized by fractional bandwidth, insertion loss, dielectric constant, return loss, circuit size and group delay. Both simulated and measured results are shown to validate the proposed filter. Finally, the MTM properties of the proposed filter have been verified by extracting its dispersion diagram. It is suitable for GSM 1800, LTE 2300 and WiMAX (5.2-5.8 GHz) application.
\end{abstract}

\section{Keywords}

Triple-band, bandpass filter, inverted S-shape resonator, C-shape stub

\section{Introduction}

In modern communication system, increasing demands of multiband services have attracted many researchers towards it. Triple-band filter with small size, low insertion loss, low cost and tremendous performance urges for multiband services [1], [2]. The main part of tri-band transceiver, a passband filter is permitted to pass on three different frequency band signals and filtering undesired frequency bands [3]. Further, various triple-band bandpass filters have been reported using different concepts [4-10]. The conventional triple-band filters were designed by cascading of multiple pair of microstrip resonators [4], which gives comparatively large size. Number of bands can be increased by using defected ground structure (DGS), which has been reported in [5]. Multiband filter has been reported using stepped impedance resonator and meandered defected ground structure, which provides compactness and flexibility to design filter structure [6]. One passband can be generated due to DGS and other passbands due to stub loaded resonators. By using the grounded stepped impedance resonator triple band filter has been designed and the bandwidth is controlled by varying the distance between two vias [7]. To enhance the electromagnetic characteristics of multiband filter multi-mode resonators have been designed in [8]. A triple-band BPF has been designed based on stub loaded open-loop resonator, which improves stopband rejection and filter performance [9]. Communication system requires different passband with different bandwidths, so design compliance is required for triple bandpass filter. In [10], independent control of bandwidths has been realized by coupling effect.

Compactness of the filter can be achieved by using metamaterial (MTM) structure due to its effective-homogeneity condition [11]. MTM are artificial engineering electromagnetic structures with negative refractive index and zero phase constant. The planar structure of metamaterial has been planted on composite right/left handed transmission line (CRLH-TL) with series inductance and capacitance along with shunt parallel inductance and capacitance circuit [12]. A work has been reported based on composite MTM and parallel step impedance resonator to get triple passband filter in addition with TZs [13]. In [14], a MTM triple-band filter has been designed using meander line and rectangular stub which realizes virtual ground concept. A compact triple band bandpass filter has been proposed using complementary split ring resonator and Koch fractal shape transmission line [15].

This manuscript proposes a compact triple-band MTM inspired bandpass filter. The filter consists of two inverted S-shape resonators and two C-shape rectangular stubs with via. The electrical circuit size of the proposed filter is $0.22 \lambda_{\mathrm{g}} \times 0.16 \lambda_{\mathrm{g}}(20.9 \mathrm{~mm} \times 15.3 \mathrm{~mm})$ at center frequency of the first passband $2.0 \mathrm{GHz}$. Center frequencies of each passband can be controlled by varying the length of S-shape resonator. Fractional bandwidth can be controlled by stub length and gap between S-shape resonators. Group delay of each passband is less than $1 \mathrm{~ns}$. 


\section{Design of Triple Band Filter}

In this paper a compact metamaterial inspired tripleband bandpass filter has been proposed and characterized using ANSYS HFSS 14.0 software. The configuration of the designed bandpass filter with optimized dimensions in caption has been displayed in Fig. 1. The equivalent LC circuit model of the designed filter has been presented in Fig. 2.

In the equivalent circuit, the series inductance $L_{\mathrm{P}}$ is generated due to input and output ports, tank circuit $L_{\mathrm{R}}, C_{1}$ (due to gap, $g_{1}$ ) appears due to the first half portion of the inverted S-shape resonator, the inductance $L_{2}$ due to the second half portion of S-shape resonator and the coupling capacitor $C_{2}$ due to gap $g_{2}$, the series left handed capacitance $C_{\mathrm{L}}$ mainly due to gap between two S-shape resonators. The LH inductance $L_{\mathrm{L}}$ is due to $\mathrm{C}$-shape stub and via which connects stub to the ground plane. The RH capacitance $C_{\mathrm{R}}$ is the patristic capacitance between C-shape stub and ground plane. The extracted lumped element values of the proposed triple band bandpass filter based on equivalent circuit diagram using advanced design system software are as follows: $L_{\mathrm{P}}=5.5 \mathrm{nH}, L_{\mathrm{R}}=0.29 \mathrm{nH}, C_{1}=2.86 \mathrm{pF}, C_{\mathrm{L}}$ $=0.89 \mathrm{pF}, C_{2}=0.63 \mathrm{pF}, L_{2}=5.4 \mathrm{nH}, C_{\mathrm{R}}=0.18 \mathrm{pF}, L_{\mathrm{L}}=1.4 \mathrm{nH}$.

The design procedure of the proposed triple band filter is divided into three major steps as shown in Fig. 3 and Fig. 4 along with scattering parameters and designed structures. The design steps are summarized as:

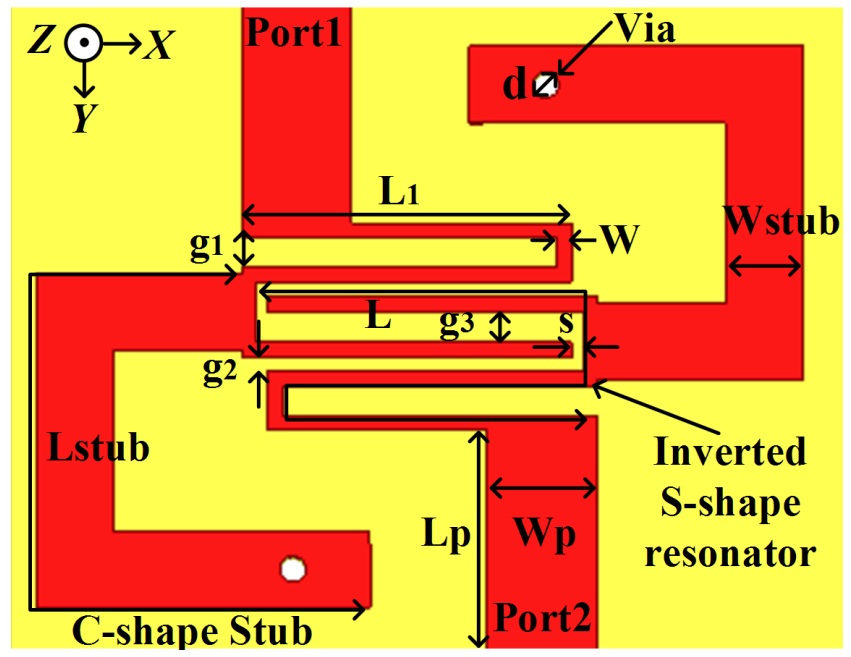

Fig. 1. Configuration of the proposed triple-band bandpass filter [All dimensions are in mm: $L=14.7, L_{1}=9.0, L_{\mathrm{p}}$ $=6.0, L_{\text {stub }}=19.6, W=0.4, W_{\mathrm{p}}=3.0, W_{\text {stub }}=2.1, \mathrm{~s}=$ $\left.0.3, g_{1}=0.8, g_{2}=0.4, g_{3}=0.8, d=0.7\right]$.

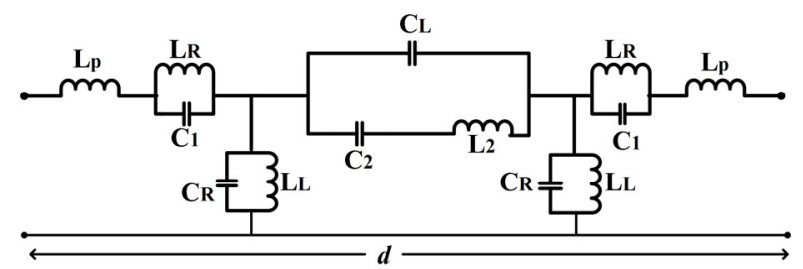

Fig. 2. Equivalent LC circuit model of the designed filter.
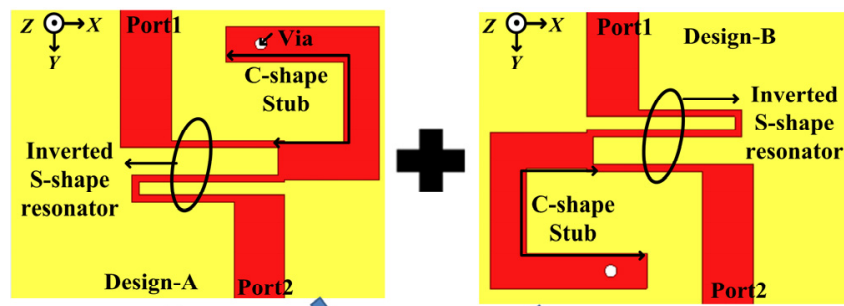

(a)

(b)

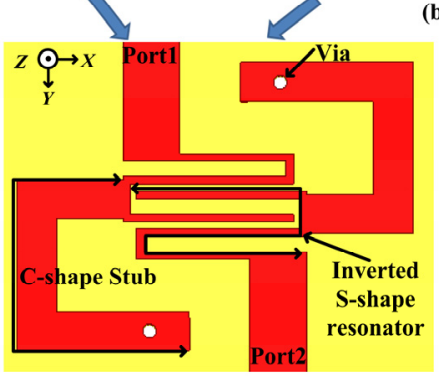

(c)

Fig. 3. Layout of different design steps of the proposed triple band filter: (a) Design-A, (b) Design-B, (c) Proposed Design-C.

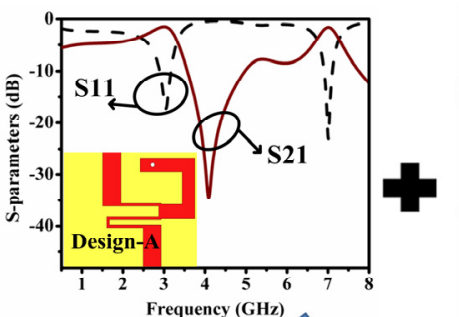

(a)

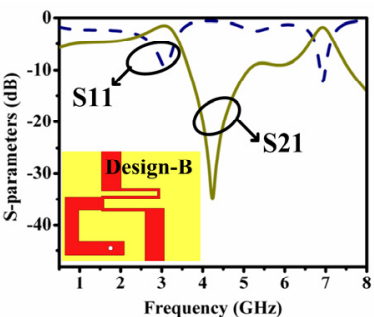

(b)

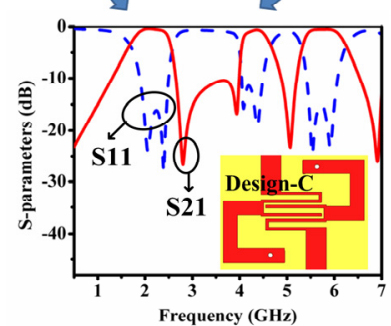

(c)

Fig. 4. Scattering parameters of different design steps of the proposed triple band filter: (a) Design-A. (b) DesignB. (c) Proposed Design-C.

(i) Step I: Initially, A dual band filter is designed with center frequencies $3.0 \mathrm{GHz}$ and $7.0 \mathrm{GHz}$ as shown in Fig. 3(a). This structure is called as Design-A and it is composed of single inverted S-shaped resonator and Cshaped rectangular stub. Via is also used in the design to connect the top and bottom copper parts. The scattering parameters of Design-A are shown in Fig. 4(a). It has insertion loss of $1.2 \mathrm{~dB}, 1.5 \mathrm{~dB}$ and return loss of $17.0 \mathrm{~dB}$, $22 \mathrm{~dB}$ at center frequencies of the first and second passband, respectively. This design has low selectivity at lower cut-off frequency of the first passband.

(ii) Step II: In the next step, an inverted mirror image layout of Design-A is formed named as Design-B as shown in Fig. 3(b). The scattering parameters of Design-B are shown in Fig. 4(b), which offers the same operating frequencies, because of symmetry. It has insertion loss of 
$1.0 \mathrm{~dB}, 1.4 \mathrm{~dB}$ and return loss of $10.0 \mathrm{~dB}$ and $12.0 \mathrm{~dB}$, respectively at center frequency of $3.0 \mathrm{GHz}$ and 7. $0 \mathrm{GHz}$. This design also offers low selectivity.

(iii) Step III: To improve the selectivity and impedance matching, Design-C has been proposed as shown in Fig. 3(c), which is the combination of Design-A and Design-B. The scattering parameters of Design-C have been depicted in Fig. 4(c), which shows a shift in center frequencies $(2.0 \mathrm{GHz}$ and $5.6 \mathrm{GHz})$ due to increase in mutual coupling between two inverted S-shape resonators formed after combining Design A and Design-B. It has also been noticed from the plot that an extra band is generated between them with center frequency of $4.25 \mathrm{GHz}$ due to improved shunt inductance.

The metamaterial properties of the proposed filter are characterized by its dispersion diagram ( $\omega-\beta$ curve), which is obtained by applying Bloch Floquet theory for a periodic distance $(d)$ of Fig. 2 [16].

$$
\beta d=\arccos \left(1+Z_{\mathrm{se}} Y_{\mathrm{sh}}\right),
$$

where

$$
\begin{gathered}
Z_{\mathrm{se}}=Z_{1}+Z_{2}, \\
Z_{1}=\mathrm{j} \omega L_{\mathrm{p}}+\mathrm{j} \omega L_{\mathrm{R}} /\left(1-\omega^{2} L_{\mathrm{R}} C_{1}\right), \\
Z_{2}=1 /\left(\mathrm{j} \omega C_{\mathrm{L}}+\mathrm{j} \omega C_{2} /\left(1-\omega^{2} L_{2} C_{2}\right)\right), \\
Y_{\mathrm{sh}}=\mathrm{j} \omega C_{\mathrm{R}}+1 /\left(\mathrm{j} \omega L_{\mathrm{L}}\right) .
\end{gathered}
$$

The dispersion diagram can also be found out using scattering parameters [17] as:

$$
\beta d=\arccos \left(\frac{1-S_{11} S_{22}+S_{12} S_{21}}{2 S_{21}}\right) .
$$

The refractive index of the designed filter using scattering parameters has been calculated using [18]

$$
\eta=\frac{-\mathrm{j}}{k d} \ln \left(\frac{S_{21}}{1-S_{11} \frac{z-1}{z+1}}\right)
$$

where $k$ and $z$ are the wave number and the impedance of the filter, respectively.

\section{Analysis of Proposed Filter}

The fabricated prototype of the proposed filter is depicted in Fig. 5. It is fabricated on FR-4 epoxy glass substrate with dielectric constant 4.4 , loss tangent 0.02 and thickness $1.6 \mathrm{~mm}$. Agilent Vector Network Analyzer N5221A has been used for scattering parameter and group delay measurement. The measured and simulated scattering parameters are presented in Fig. 6.

The measured and simulated results are in acceptable agreement with each other; there are minor frequency shift

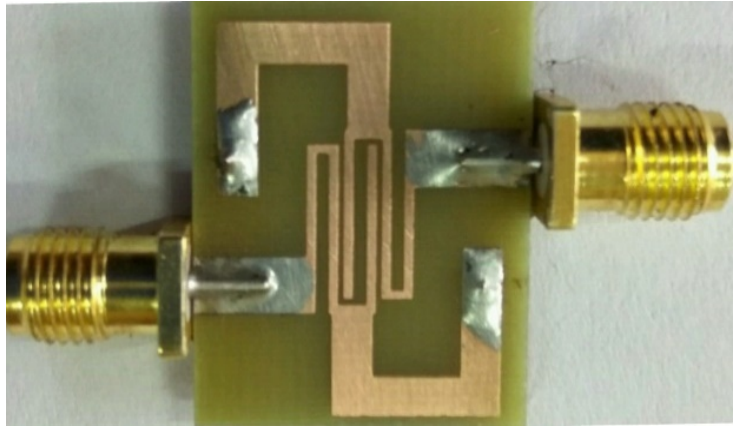

Fig. 5. Fabricated prototype of the presented filter.

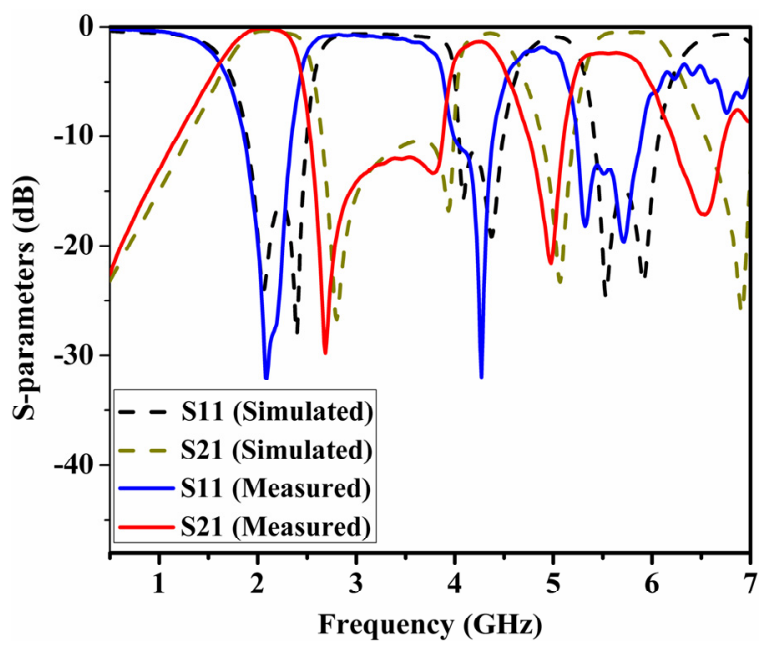

Fig. 6. Measured and simulated scattering parameters.

in center frequencies and more insertion loss in the second and third passband in comparison with simulation. These shifts have occurred due to imperfection of substrate and connector loss. The measured insertion losses have been found to be $0.1,1.2$, and $2.2 \mathrm{~dB}$ in triple-band at 2.0, 4.25, and $5.26 \mathrm{GHz}$ respectively. The in-band return losses are greater than 32,32 , and $13 \mathrm{~dB}$ with fractional bandwidth $40.0,16.5$, and $14.3 \%$ respectively with respect to their center frequencies. In simulation total six poles are generated, two poles by each passband. They are situated at $2.05,2.38,4.0,4.36,5.52$ and $5.9 \mathrm{GHz}$ and their center frequencies at $f_{\mathrm{c} 1}=2.1 \mathrm{GHz}, f_{\mathrm{c} 2}=4.32 \mathrm{GHz}$, and $f_{\mathrm{c} 3}=5.76 \mathrm{GHz}$ for the first, second and third passband, respectively.

The simulated surface current density of the proposed filter at six pole frequencies of passbands has been shown in Fig. 7. It depicts that the first and second pole frequency (2.05 and $2.38 \mathrm{GHz}$ ) of the first passband are mainly due to S-shape resonator and via, the third pole frequency $(4.0 \mathrm{GHz})$ is due to whole structure and the fourth, fifth and sixth pole frequencies $(4.36,5.52$, and $5.9 \mathrm{GHz}) \mathrm{de}-$ pend on S-shape resonator because high surface current density is concentrated on it. The simulated dispersion diagram of the designed triple band bandpass filter is shown in Fig. 8. It shows that passbands have both positive and negative slope, known as CRLH region. The passband from 1.6 to $1.85 \mathrm{GHz}, 4.3$ to $4.6 \mathrm{GHz}$, and 5.3 to $6.0 \mathrm{GHz}$ with their negative slope termed as left handed (LH) region. 


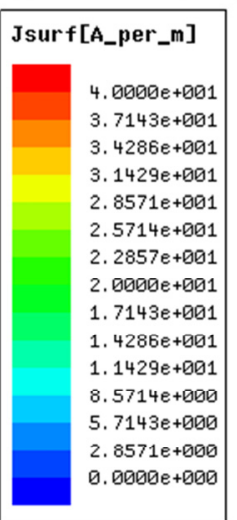

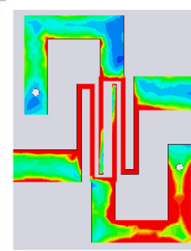

(a)

(d)

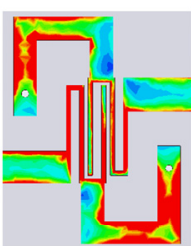

b)

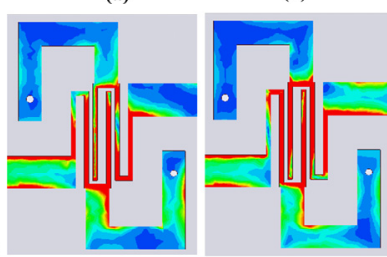

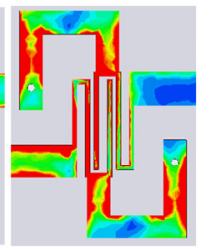

(c)

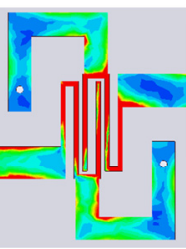

(f)
Fig. 7. Simulated surface current density of the proposed filter at pole frequencies of the triple band filter: (a) $2.05 \mathrm{GHz}, \quad$ (b) $2.38 \mathrm{GHz}, \quad$ (c) $4.0 \mathrm{GHz}$, (d) $4.36 \mathrm{GHz}$, (e) $5.52 \mathrm{GHz}$, (f) $5.9 \mathrm{GHz}$.

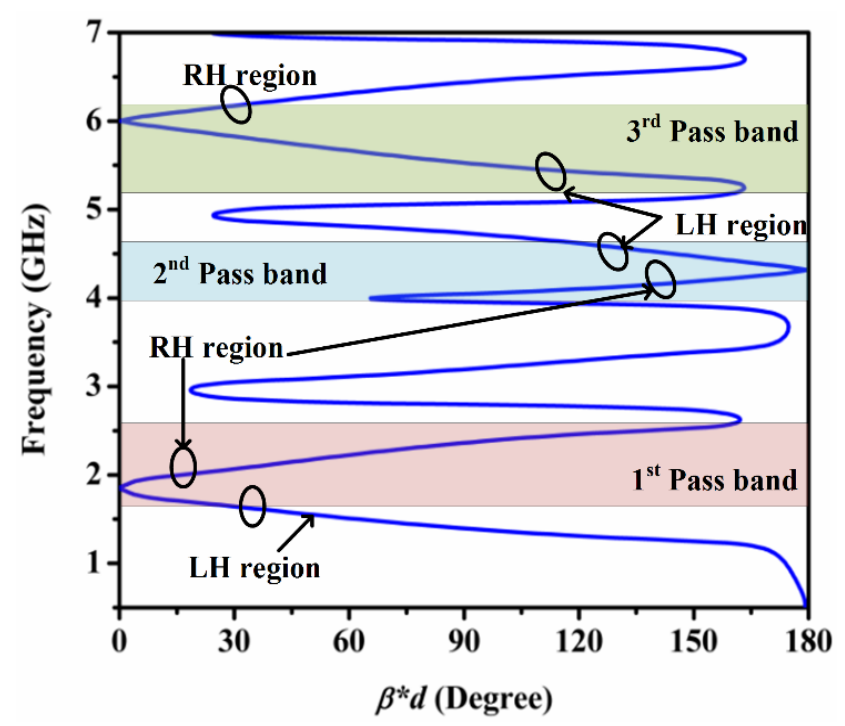

Fig. 8. Simulated dispersion diagram of the designed filter.

Similarly passbands from 1.85 to $2.55 \mathrm{GHz}, 3.9$ to $4.3 \mathrm{GHz}$, and 6.0 to $6.2 \mathrm{GHz}$ are known as right handed $\mathrm{RH}$ ) region due to positive slope. This verifies the MTM properties of the designed filter, zero phase constant at frequency $1.85 \mathrm{GHz}$ is known as the zeroth order resonance frequency.

The refractive index of the proposed filter is depicted in Fig. 9. It depicts that at resonance frequencies of the first and second passbands the real value of the refractive index is negative.

Group delay is the important parameter for bandpass filter. It measures the rate of change of transmission phase angle with respect to frequency. The group delay of the designed filter is depicted in Fig. 10. The measured variation of group delay within the passband varies from 0.5 to $1.0 \mathrm{~ns}$. There has been a little difference of $0.3 \mathrm{~ns}$ between simulated and measured group delay due to imperfection in soldering and connector losses.

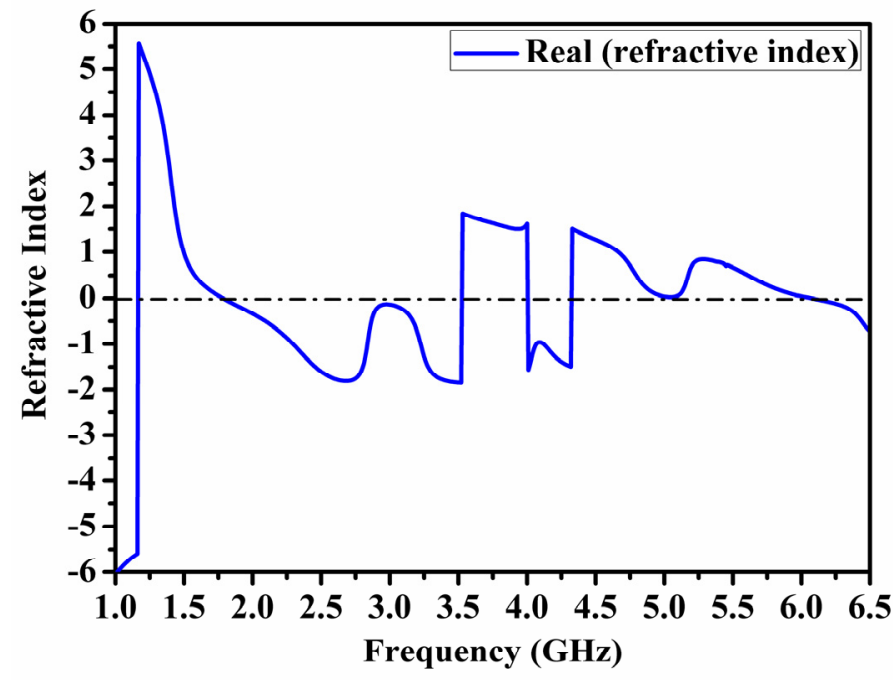

Fig. 9. Simulated refractive index of the proposed filter.

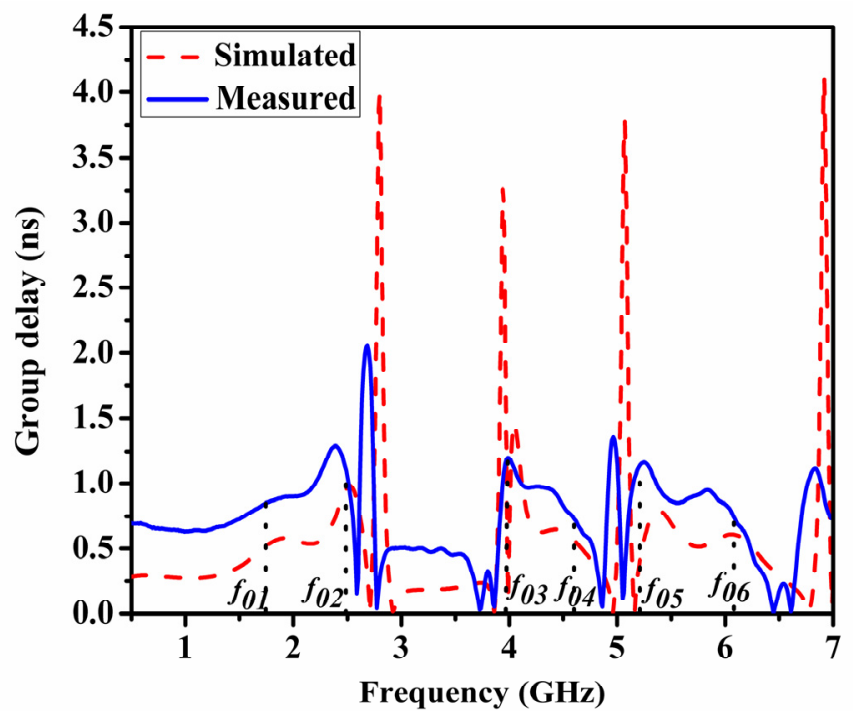

Fig. 10. Measured and simulated group delay.

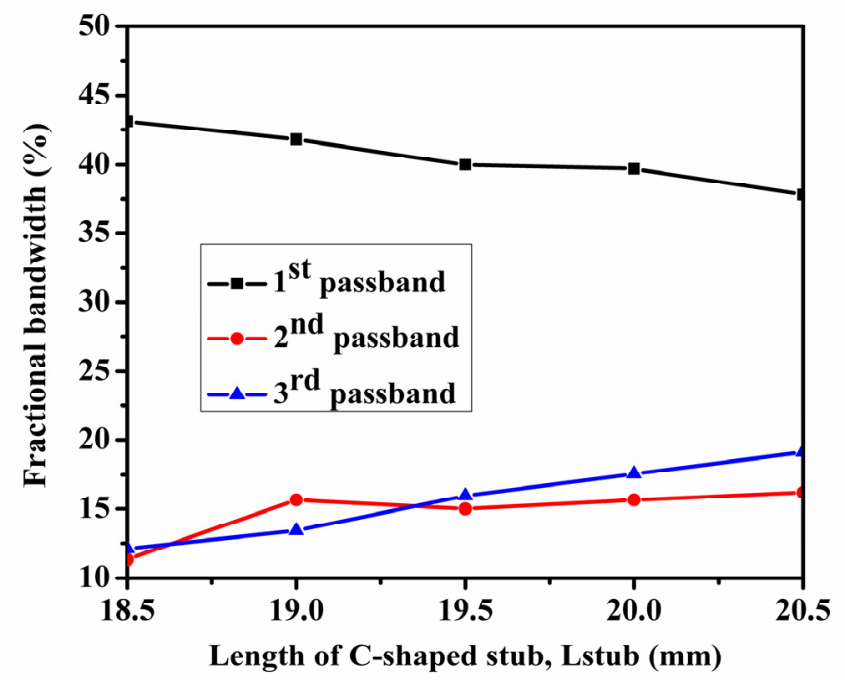

Fig. 11. Variation of fractional bandwidth with $L_{\text {stub }}$. 
The $3 \mathrm{~dB}$ fractional bandwidth is the important parameter of bandpass filter. It is defined as the ratio of bandwidth and center frequency. Variation of fractional bandwidth with different values of C-shape stub length is depicted in Fig. 11. As the length of $L_{\text {stub }}$ increases from 18.5 to $20.5 \mathrm{~mm}$ the fractional bandwidth of the first passband increases from 43.1 to $37.8 \%$, in the second passband it varies randomly and in the third passband it increases with the length of the stub. The dependency of fractional bandwidth with change in gap $g_{3}$ between $\mathrm{S}$-shape resonator is shown in Fig. 12. By changing $g_{3}$ from 0.4 to $1.2 \mathrm{~mm}$ the fractional bandwidth decreases for the first and second passband and increases in the third passband.

The dependency of center frequencies on series inductance, $L_{\mathrm{R}}$ due to current flowing in the first arm of Sshape resonator is shown in Fig. 13. The center frequencies $\left(f_{\mathrm{c} 1}, f_{\mathrm{c} 2}\right.$ and $\left.f_{\mathrm{c} 3}\right)$ of all three passbands decrease by increasing the length $L_{1}$. A comparison of measured values of the proposed triple band filter with earlier published triple band filters is summarized in Tab. 1. In terms of the center frequencies, return loss, insertion loss, $3 \mathrm{~dB}$ fractional band-

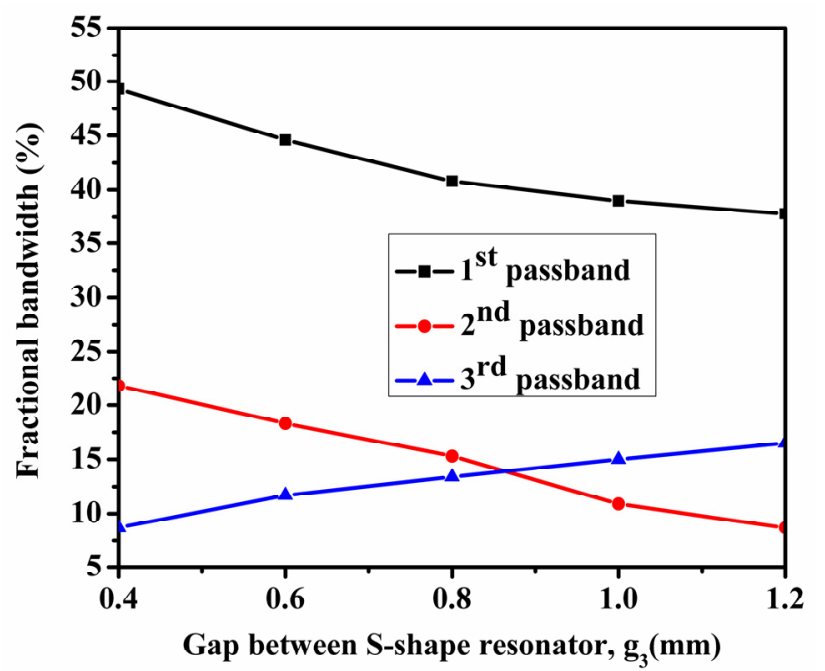

Fig. 12. Variation of the fractional bandwidth with gap $g_{3}$.

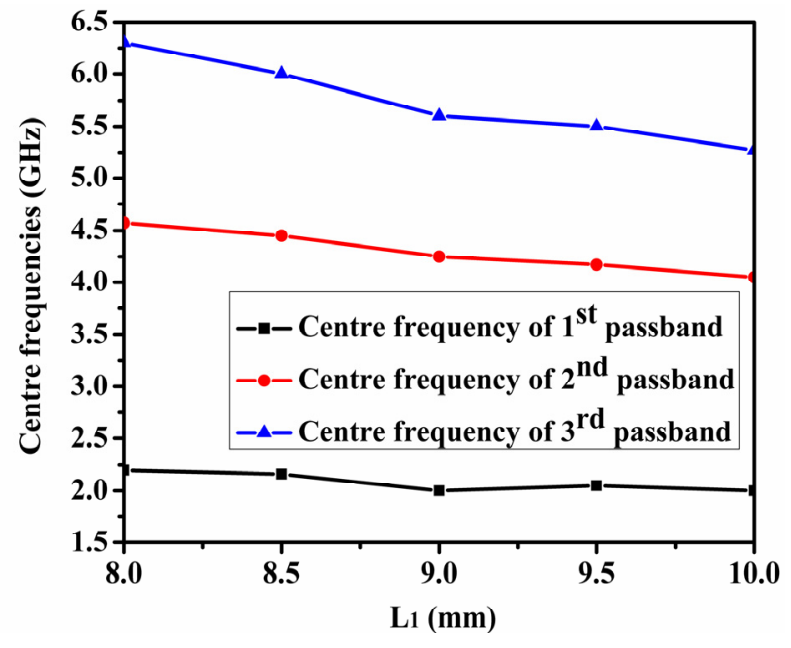

Fig. 13. Variation of the center frequencies with length $L_{1}$.

\begin{tabular}{|c|c|c|c|c|c|}
\hline & This work & {$[7]$} & {$[\mathbf{8}]$} & {$[\mathbf{9 ]}$} & {$[\mathbf{1 4}]$} \\
\hline $\begin{array}{c}\mathrm{CF} \\
(\mathrm{GHz})\end{array}$ & $\begin{array}{c}\mathbf{2 . 0 / 4 . 2 5} \\
\mathbf{5 . 6}\end{array}$ & $\begin{array}{c}2.45 / 3.5 \\
/ 5.3\end{array}$ & $\begin{array}{c}1.95 / 3.65 \\
/ 3.92\end{array}$ & $\begin{array}{c}1.93 / 3.6 \\
/ 4.89\end{array}$ & $\begin{array}{c}2.1 / 5 / 7 \\
/ 7.3\end{array}$ \\
\hline $\begin{array}{c}\mathrm{FBW} \\
(\%)\end{array}$ & $\begin{array}{c}\mathbf{4 0 / 1 6 . 5} \\
/ \mathbf{1 4 . 3}\end{array}$ & $\begin{array}{c}14 / 7 \\
/ 4\end{array}$ & $\begin{array}{c}8.5 / 3.7 \\
/ 3.9\end{array}$ & $\begin{array}{c}19.2 / 11.6 \\
/ 2.86\end{array}$ & $\begin{array}{c}57.1 / 8.7 \\
/ 4.1\end{array}$ \\
\hline $\mathrm{IL}(\mathrm{dB})$ & $\begin{array}{c}\mathbf{0 . 1} / \mathbf{1 . 2} \\
\mathbf{2} .2\end{array}$ & $\begin{array}{c}0.9 / 1.7 \\
/ 2.1\end{array}$ & $\begin{array}{c}0.46 / 1.96 \\
/ 1.15\end{array}$ & - & $\begin{array}{c}0.8 / 1.6 \\
/ 2.4\end{array}$ \\
\hline $\mathrm{RL}(\mathrm{dB})$ & $\mathbf{3 2 / 3 2} />\mathbf{1 3}$ & $37 / 15 / 15$ & $>16.7$ & $15 / 15 / 22$ & $25.5 / 15 / 23$ \\
\hline $\mathrm{DC}$ & $\mathbf{4 . 4}$ & 3.5 & 2.65 & 10.2 & 4.4 \\
\hline $\begin{array}{c}\mathrm{CS} \\
\left(\lambda_{\mathrm{g}} \times \lambda_{\mathrm{g}}\right)\end{array}$ & $\mathbf{0 . 2 2} \times \mathbf{0 . 1 6}$ & $0.43 \times 0.35$ & $0.38 \times 0.28$ & $0.33 \times 0.23$ & $0.23 \times 0.21$ \\
\hline
\end{tabular}

$\mathrm{CF}=$ center frequencies, $\mathrm{FBW}=3 \mathrm{~dB}$ fractional bandwidth, $\mathrm{IL}=$ insertion loss, $\mathrm{RL}=$ return loss, $\mathrm{DC}=$ dielectric constant, $\mathrm{CS}=$ circuit size.

Tab. 1. Comparison of the designed filter with earlier published triple band bandpass filters.

width and electrical circuit size, it can be claimed that the proposed filter is very powerful candidate to earlier published performance.

\section{Conclusion}

A compact metamaterial inspired triple-band bandpass filter using S-shape resonator, $\mathrm{C}$-shape stub and via has been proposed. The center frequency of all the three passbands depends on right handed inductance $L_{\mathrm{R}}$. The dependency of fractional bandwidth on the length of Cshape stub has been explained. The proposed filter has good agreement with simulated and measured results. The proposed filter has three passbands from 1.6-2.4 GHz, 3.9-4.6 GHz and 5.2-5.6 GHz. It has compact electrical circuit size of $0.22 \lambda_{\mathrm{g}} \times 0.16 \lambda_{\mathrm{g}}$, at center frequency of the first passband. The proposed filter is suitable for GSM $(1.8 \mathrm{GHz})$, LTE $(2.3 \mathrm{GHz})$, WLAN $(5.2$ to $5.8 \mathrm{GHz})$ applications.

\section{References}

[1] HSU, C. G., LEE, C., HSIEH, Y. Tri-band bandpass filter with sharp passband skirts designed using tri-section SIRs. IEEE Microwave and Wireless Components Letters, 2008, vol. 18, no. 1, p. 19-21. DOI: 10.1109/LMWC.2007.911976

[2] HONG, J. S. Microstrip Filters for RF/Microwave Applications. 2nd ed. New York: Wiley, 2011. ISBN: 978-0-470-40877-3

[3] WANG, W., LI, Y., CAO, Q., YANG, S., CHEN, Y. Design of triple-bandpass filters using an asymmetric stepped-impedance ring resonator. Progress In Electromagnetics Research Letters, 2017, vol. 67, p. 7-12. DOI: 10.2528/PIERL17011605

[4] CHEN, B. J., SHEN, T. M., WU, R. B. Design of tri-band filters with improved band allocation. IEEE Transactions on Microwave Theory and Techniques, 2009, vol. 57, no. 7, p. 1790-1797. DOI: 10.1109/TMTT.2009.2022888

[5] LAI, X., LIANG, C. H., DI, H., WU, B. Design of tri-band filter based on stub loaded resonator and DGS resonator. IEEE Microwave and Wireless Components Letters, 2010, vol. 20, no. 5, p. 265-267. DOI: 10.1109/LMWC.2010.2045584 
[6] KOIRALA, G. R., KIM, N. Y. Multiband bandstop filter using an I-stub-loaded meandered defected microstrip structure. Radioengineering, 2016, vol. 25, no. 1, p. 61-66, DOI: $10.13164 /$ re.2016.0061

[7] MO, Y., SONG, K., FAN, Y. Miniaturized triple-band bandpass filter using coupled lines and grounded stepped impedance resonators. IEEE Microwave and Wireless Components Letters, 2014, vol. 24, no. 5, p. 333-335. DOI: 10.1109/LMWC.2014.2310458

[8] FAN, W. X., LI, Z. P., GONG, S. X. Tri-band filter using combined E-type resonators. Electronics Letters, 2013, vol. 49, no. 3, p. 193-194. DOI: 10.1049/el.2012.3617

[9] KUMAR, N., SINGH, Y. K. Compact tri-band bandpass filter using three stub-loaded open-loop resonator with wide stopband and improved bandwidth response. Electronics Letters, 2014, vol. 50, no. 25, p. 1950-1952. DOI: 10.1049/el.2014.3425

[10] GAO, L., ZHANG, X. Y., ZHAO, X. L., et al. Novel compact quad-band bandpass filter with controllable frequencies and bandwidths. IEEE Microwave and Wireless Components Letters, 2016, vol. 26, no. 3, p. 395-397. DOI: 10.1109/LMWC.2016.2558038

[11] CALOZ, C., ITOH, T. Electromagnetic Metamaterials: Transmission Line Approach and Microwave Applications. Hoboken (NJ, USA): Wiley, 2006. ISBN-10: 0-471-66985-7

[12] CHOUDHARY, D. K., CHAUDHARY, R. K. A compact coplanar waveguide (CPW)-fed zeroth-order resonant filter for bandpass applications. Frequenz Journal of RF-Engineering and Telecommunications, 2017, vol. 71, p. 305-310. DOI: 10.1515/freq-2016-0147

[13] CAO, H., YI, M., CHEN, H., et al. A novel compact tri-band bandpass filter based on dual-mode CRLH-TL resonator and transversal stepped impedance resonator. Progress In Electromagnetics Research Letters, 2015, vol. 56, p. 53-58. DOI: 10.2528/PIERL15080403

[14] KUMAR, A., CHOUDHARY, D. K., CHAUDHARY, R. K. Metamaterial tri-band bandpass filter using meander-line with rectangular-stub. Progress In Electromagnetics Research Letters, 2017, vol. 66, p. 121-126. DOI: 10.2528/PIERL16123103

[15] XU, H. X., WANG, G. M., LIANG, J. G. Novel designed CSRRs and its application in tunable tri-band bandpass filter based on fractal geometry. Radioengineering, 2011, vol. 20, no. 2, p. $312-316$. ISSN: $1210-2512$

[16] FOUAD, M. A., ABDALLA, M. A. New $\pi-T$ generalised metamaterial negative refractive index transmission line for a compact coplanar waveguide triple band pass filter applications. IET Microwaves, Antennas and Propagation, 2014, vol. 8, no. 13 , p. 1097-1104. DOI: 10.1049/iet-map.2013.0698

[17] KUMAR, A., CHOUDHARY, D. K., CHAUDHARY, R. K. Triple-band composite right/left handed bandpass filter using a new circular inter-digital capacitor for wireless applications. Progress In Electromagnetics Research C, 2017, vol. 71, p. 133-140, 2017. DOI: 10.2528/PIERC16122903

[18] NUMAN, A. B., SHARAWI, M. S. Extraction of material parameters for metamaterials using a full-wave simulator. IEEE
Antennas and Propagation Magazine, 2013, vol. 55, no. 5, p. 202-210. DOI: 10.1109/MAP.2013.6735515

\section{About the Authors...}

Dilip Kumar CHOUDHARY was born in Purnea, Bihar, India. He is pursuing Ph.D. from the Dept. of Electronics Engineering, Indian Institute. of Technology (Indian School of Mines), Dhanbad, India and getting fellowship from MHRD, Government of India. He did his M.E. degree from the Birla Institute of Technology, Ranchi, India in 2012, where he got fellowship from MHRD Govt. of India. He has done his B. Tech. degree from Biju Patnaik University, Orissa, India in 2009. He has authored more than 19 referred journal and conference papers. He was the recipient of the International Travel Grant form DST, India in 2017. He was the recipient of the Best Student Paper (Third Position) at PIERS, Singapore in 2017. He is a student member of IEEE. His current research interests include metamaterial and its application in filters, antennas and absorbers.

Raghvendra Kumar CHAUDHARY is working as an Assistant Professor at the Dept. of Electronics Engineering, Indian Institute of Technology (Indian School of Mines), Dhanbad, India. He did his Ph.D. from the Indian Inst. of Technology Kanpur, India in Jan. 2014, the M.Tech. degree from the Indian Inst. of Technology (BHU), Varanasi, India, in 2009 and the B.Tech. degree from the University Inst. of Engineering and Technology, Kanpur India, in 2007. Dr. Chaudhary has authored more than 130 referred journal and conference papers. He was the recipient of the International Travel Grant form CSIR, DST and IIT Kanpur, India. He was the recipient of the Best Student Paper Bronze Award at IEEE APACE, Malaysia in 2010 and also recipient of the Best Paper Award at ATMS, India in 2012. $\mathrm{He}$ is associate editor of IEEE Access, Member of IEEE and potential reviewer of many journals and conferences such as IEEE Transactions on Antennas \& Propagation, IEEE AWPL, IET MAP, IET Electronics Letters etc. His current research interests involve metamaterials, dielectric resonators, and computational electromagnetics. $\mathrm{He}$ is presently handling many research projects in the capacity of Principal Investigator sponsored from Indian funding agencies like SERB(DST), ISRO etc. 